\title{
Surveillance of chronic obstructive pulmonary disease in high-risk individuals by using regional lung cancer mass screening
}

This article was published in the following Dove Press journal:

International Journal of COPD

23 June 2014

Number of times this article has been viewed

\author{
Yasuo Sekine \\ Ryoko Yanagibori \\ Kiminori Suzuki \\ Sonomi Sugiyama \\ Haruko Yamaji \\ Michiko Ishibashi \\ Takehiko Fujisawa \\ Chiba Foundation for Health \\ Promotion and Disease \\ Prevention, Chiba, Japan
}

Correspondence: Takehiko Fujisawa Chiba Foundation for Health Promotion and Disease Prevention, 32-I4 Shinminato, Mihama-ku, Chiba 26I-0002, Japan

$\mathrm{Tel}+8 \mathrm{I} 432460350$

Fax +8I 43248640

Email ta-fujisawa@kenko-chiba.or.jp
Background and objective: Patients with chronic obstructive pulmonary disease (COPD) are at risk for lung cancer; the diseases have common etiologies, including cigarette smoking. We aimed to clarify the effectiveness of COPD detection using a regional mass-screening program for lung cancer.

Materials and methods: A total of 7,067 residents of Togane, Chiba, Japan received lung cancer screening between May and July, 2011. We defined four groups of possible COPD candidates: group A ( $\mathrm{n}=358)$, positive smoking history, positive chronic respiratory symptoms; group B ( $n=766)$, positive smoking history, positive lifestyle-related disease; group $C(n=75)$, passive smoking history, positive chronic respiratory symptoms; and group $D(n=301)$, passive smoking history, positive lifestyle-related disease. Candidates underwent on-site pulmonary function testing (PFT).

Results: The criteria for COPD candidates were fulfilled in 1,686 of 7,067 individuals (23.9\%); 1,500 participants underwent PFT (89\%), and 171 (11.4\%) were diagnosed with COPD. The overall COPD detection rate was $2.4 \%$. The frequency of COPD was significantly higher in groups $\mathrm{A}$ and $\mathrm{B}$ than in groups $\mathrm{C}$ and $\mathrm{D}(P=0.048)$; however, the distribution of COPD grades was similar among the groups $(P=0.372)$. Multiple logistic regression analysis identified male sex, age 60 years or greater, and positive smoking history as risk factors for COPD.

Conclusion: COPD screening using a community-based lung cancer-screening program may be effective for disease detection. Individuals who are 60 years of age or older with a positive smoking history should undergo PFT to detect COPD.

Keywords: chronic obstructive pulmonary disease, lung neoplasms, mass screening, respiratory function tests

\section{Introduction}

Chronic obstructive pulmonary disease (COPD), although a rapidly growing health problem worldwide, is substantially underdiagnosed ${ }^{1,2}$ and frequently misdiagnosed. ${ }^{3}$ Soriano et $\mathrm{al}^{2}$ reported that $72 \%-93 \%$ of COPD patients are not properly diagnosed. The Nippon COPD Epidemiology study reported that the prevalence of airflow limitation, defined as a ratio of forced expiratory volume in 1 second $\left(\mathrm{FEV}_{1}\right)$ to forced vital capacity (FVC) less than $70 \%$, was $10.9 \%$, but only $9.4 \%$ of patients with airflow limitation had actually been diagnosed with COPD. ${ }^{4}$ Although the gold standard for diagnosis is spirometry, the technique is used for only $30 \%-50 \%$ of new cases in general practice. ${ }^{5,6}$ Therefore, it is very difficult to detect COPD at the early stages, which would allow for smoking-cessation counseling and prevention of disease progression.

Both COPD and cigarette smoking induce systemic inflammatory changes that result from localized chronic inflammation in the lung. COPD is not only a pulmonary 
disease but also a systemic inflammatory disease that leads to various comorbidities, including coronary artery disease, congestive heart disease, lung cancer, osteoporosis, and neurological disease. ${ }^{7,8}$ Patients with COPD have an average of 3.7 chronic comorbidities, while those without COPD have only $1.8 .{ }^{8}$ Chatila et al determined that lifestyle-related diseases, including hypertension, angina pectoris, diabetes mellitus, dyslipidemia, and osteoporosis, are common in COPD patients. ${ }^{9}$ This suggests that it may be possible to detect COPD by performing pulmonary function testing (PFT) in patients with lifestyle-related disease.

Approximately $30 \%$ of Japanese individuals over 40 years of age receive annual community-based mass screening for lung cancer using chest radiography. Several questionnaires are utilized during this screening that may determine patients' risk levels for lung cancer and COPD. The aim of this study was to clarify the effectiveness of regional mass screening for lung cancer in detecting early stage COPD in a Japanese population.

\section{Materials and methods Ethics}

The study protocol was approved by the Togane Ethics Committee in the Chiba Administrative Agency and by the Institutional Review Board Committee of the Chiba Foundation for Health Promotion and Disease Prevention. Each participant provided written informed consent for participation.

\section{Study design}

The use of chest radiography for community-based lung cancer screening in Japan is well established, ${ }^{10,11}$ and has been supported by the national government under the Health and Medical Services Law for the Aged since 1987. Japanese individuals 40 years of age and older consult with public health nurses and provide their health habits and past and current medical histories on a lifestyle questionnaire. Individuals then undergo annual chest radiography. All holders of National Health Insurance and family members of individuals with employment-related health insurance are eligible for this screening; holders of employment-related health insurance are screened by their companies under a different system. Individuals suspected of having lung cancer based on the results of chest radiography or sputum cytology undergo a secondary evaluation and examination to confirm the diagnosis.

Togane in Chiba Prefecture is $60 \mathrm{~km}$ east of Tokyo and is in a typical rural area, with main industries of agriculture and construction. In 2012, the population of Togane was 59,250. The study subjects were residents of Togane who had received lung cancer screening between May and July, 2011. The individuals underwent screening in a public assembly hall, where they filled out detailed questionnaires about their occupation, alcohol intake, smoking status, past and current medical history, and any chronic symptoms. For the purposes of this study, we paid particular attention to the questions about smoking history, passive smoking history, chronic respiratory symptoms, and lifestyle-related diseases, including hypertension, angina pectoris/myocardial infarction, diabetes mellitus, dyslipidemia, and osteoporosis. We defined two criteria to identify possible COPD candidates: 1) individuals with a positive smoking history, either current or past, or a passive smoking history, either at home or in the workplace; and 2) individuals with chronic respiratory symptoms or lifestyle-related disease. When residents fulfilled both criteria, they were considered COPD candidates and advised to undergo PFT. Two certified medical laboratory technicians administered this testing. No bronchodilators were used, and the best result of three was used as the test result. The functional diagnosis of COPD was defined as forced expiratory volume in 1 second $\left(\mathrm{FEV}_{1}\right)$ /forced vital capacity (FVC) less than 70\%. The classification of COPD stage was based on GOLD (Global initiative for chronic Obstructive Lung Disease) staging: mild COPD, percentage predicted $\mathrm{FEV}_{1}>80 \%$; moderate $\mathrm{COPD}$, percentage predicted $\mathrm{FEV}_{1}<80 \%$ but $>50 \%$; severe COPD, percentage predicted $\mathrm{FEV}_{1}<50 \%$ but $>30 \%$; very severe COPD, percentage predicted $\mathrm{FEV}_{1}<30 \%$. $^{12}$ Individuals who refused to undergo PFT and those who could not perform PFT well were excluded from analysis.

We divided COPD candidates into the following four groups (Figure 1): group A, positive smoking history and positive chronic respiratory symptoms, including cough, cough producing sputum, and dyspnea on effort; group B, positive smoking history, no chronic respiratory symptoms, and positive lifestyle-related disease; group $\mathrm{C}$, passive smoking history and positive chronic respiratory symptoms; group D, passive smoking history, no chronic respiratory symptoms, and positive lifestyle-related disease.

Once participants were diagnosed with COPD, they were instructed to receive chest computed tomography to identify radiological emphysema, the severity of which was visually assessed by two independent pulmonary specialists, in a blinded fashion, according to the modified Goddard scoring system. ${ }^{13,14}$ Three lung slices, with right and left lungs evaluated separately for a total of six images, were analyzed for each participant. Each image was classified and scored: 


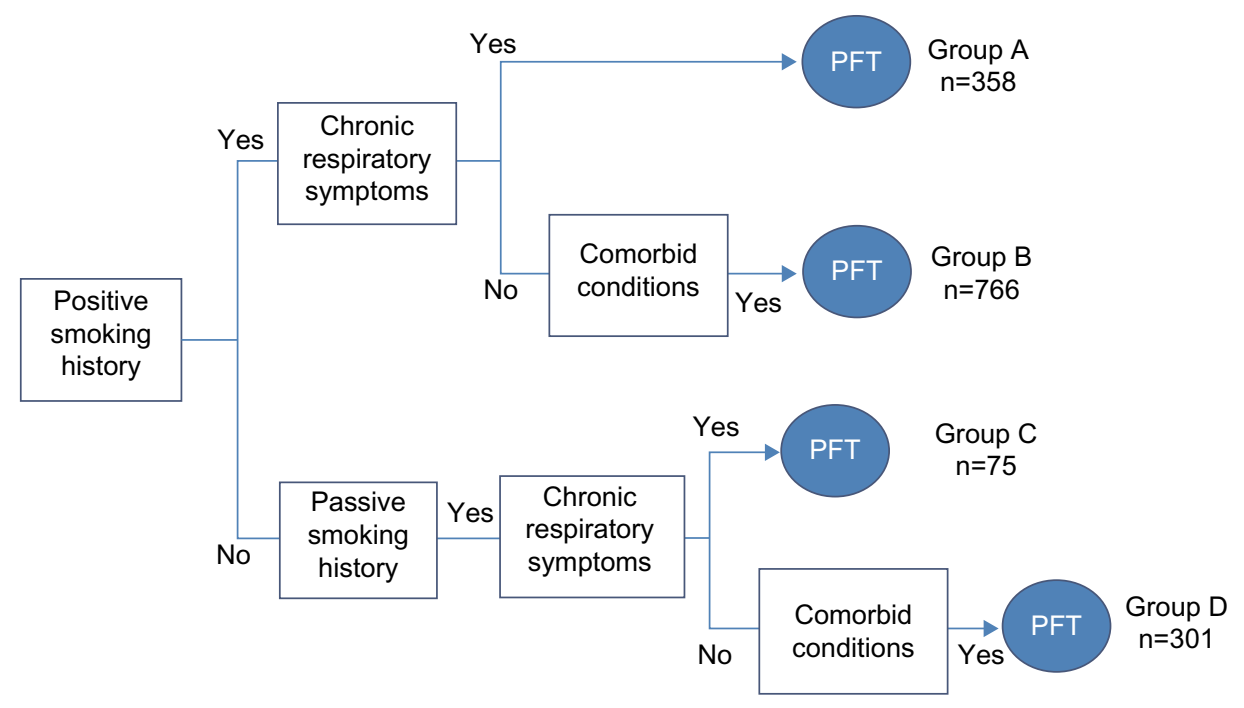

Figure I Algorithm of screening for chronic obstructive pulmonary disease (COPD).

Notes: We divided COPD candidates into the following four groups: group A, positive smoking history and positive chronic respiratory symptoms including cough, cough producing sputum, and dyspnea on effort; group B, positive smoking history, no chronic respiratory symptoms, and positive lifestyle-related disease; group C, passive smoking history and positive chronic respiratory symptoms; group D, passive smoking history, no chronic respiratory symptoms, and positive lifestyle-related disease. Comorbid conditions - lifestyle-related disease: hypertension, angina pectoris/myocardial infarction, diabetes mellitus, dyslipidemia, and osteoporosis.

Abbreviation: PFT, pulmonary function test.

normal, score $0 ; \leq 5 \%$ affected, score $0.5 ; \leq 25 \%$ affected, score $1 ; \leq 50 \%$ affected, score $2 ; \leq 75 \%$ affected, score 3 ; and $>75 \%$ affected, score 4 . The mean score of the six images was considered to be representative of emphysema severity. The participants were then classified into three groups based on the severity of emphysema: 1) no/mild emphysema (emphysema score $<1$, average percentage low-attenuation area in the assessed lung $<12.5 \%$ ); 2) moderate emphysema (emphysema score 1-2.5, average percentage low-attenuation area in the assessed lung $<50 \%$ ); and 3) severe emphysema (emphysema score $\geq 2.5$, average percentage low-attenuation area in the assessed lung $\geq 50 \%$ ).

\section{Statistical analysis}

Data were analyzed using SPSS version 19 (IBM, Armonk, NY, USA). The $\chi^{2}$ test was used to analyze categorical variables, and the Kruskal-Wallis test was used for continuous variables. The relation between two quantitative variables was examined using the Spearman rank correlation test. Possible predictor variables, including patient sex, age, smoking status, and the presence of lifestyle-related disease, were assessed as risk factors for COPD using multiple regression analysis. A significance level of 5\% was adopted, and the significance of predictor variables was tested using the likelihood-ratio test.

\section{Results}

Of the 7,067 total participants (2,720 male and 4,347 female), COPD candidate criteria were fulfilled in
1,686 (23.9\%), and 1,500 of these underwent PFT. We excluded from analysis 153 individuals who refused to undergo PFT and 23 who could not perform PFT well; a total of 1,500 participants $(21.2 \%)$ were included in the study.

Of those who underwent PFT, 171 (11.4\%) were diagnosed with COPD, yielding a COPD detection rate of $2.4 \%$ (171 of 7,067). Table 1 shows the characteristics of the possible COPD candidates according to group: group A consisted of 358 subjects, group B had 766 subjects, group C had 75 subjects, and group D had 301 subjects. In groups A and $\mathrm{B}$, there was a significantly higher proportion of male patients than in groups $\mathrm{C}$ and $\mathrm{D}(P<0.001)$. Age, smoking status, and lifestyle-related disease distribution were also significantly different among the four groups $(P<0.001)$. Table 2 shows the distribution of COPD severity and PFT results. The frequency of COPD was significantly higher in groups $\mathrm{A}$ and $\mathrm{B}$ than in groups $\mathrm{C}$ and $\mathrm{D}(P=0.048)$; however, the distribution of COPD grades was similar in the four groups $(P=0.372)$. Although the values for $\mathrm{FEV}_{1} / \mathrm{FVC}$ were similar across all groups $(P=0.185)$, the mean value in groups $\mathrm{A}$ and $\mathrm{B}$ was significantly lower than in groups $\mathrm{C}$ and $\mathrm{D}(P=0.003)$. The percentage predicted $\mathrm{FEV}_{1}$ was significantly worse in groups $\mathrm{A}$ and $\mathrm{B}$ than in groups $\mathrm{C}$ and $\mathrm{D}$ $(P<0.001)$. Table 3 shows the characteristics of participants who were diagnosed with COPD. Male sex and higher age were significantly more common in groups $\mathrm{A}$ and $\mathrm{B}$ than in groups $\mathrm{C}$ and $\mathrm{D}(P<0.001)$. 
Table I Characteristics of COPD candidates

\begin{tabular}{|c|c|c|c|c|c|c|}
\hline & $\begin{array}{l}\text { Group A } \\
(n=358)\end{array}$ & $\begin{array}{l}\text { Group B } \\
(n=766)\end{array}$ & $\begin{array}{l}\text { Group C } \\
(n=75)\end{array}$ & $\begin{array}{l}\text { Group D } \\
(n=301)\end{array}$ & Total & $P$-value \\
\hline Male/female & $277 / 81$ & $613 / 153$ & $9 / 66$ & $27 / 274$ & $926 / 574$ & $<0.001$ \\
\hline Male \% & $77.4 \%$ & $80.0 \%$ & $12.0 \%$ & $9.0 \%$ & & \\
\hline Age (years) & & & & & & $<0.001$ \\
\hline $40-49$ & $61(17.0 \%)$ & 30 (3.9\%) & 17 (22.7\%) & $2(0.7 \%)$ & 110 & \\
\hline $50-59$ & $60(16.8 \%)$ & 76 (9.9\%) & $16(21.3 \%)$ & $44(14.6 \%)$ & 196 & \\
\hline $60-69$ & I 25 (34.9\%) & 301 (39.3\%) & $3 \mid(4 \mid .3 \%)$ & I 44 (47.8\%) & 601 & \\
\hline $70-79$ & $95(26.5 \%)$ & $269(35.1 \%)$ & $10(13.3 \%)$ & $85(28.3 \%)$ & 459 & \\
\hline $80+$ & 17 (4.8\%) & $90(11.8 \%)$ & I (I.4\%) & $26(8.6 \%)$ & 134 & \\
\hline Mean \pm standard deviation & $62.6 \pm 11.2$ & $68.5 \pm 9.2$ & $59.2 \pm 10.5$ & $67.2 \pm 8.0$ & $66.4 \pm 10.0$ & $<0.001$ \\
\hline Median & 64.0 & 69.0 & 61.0 & 66.0 & 67.0 & \\
\hline Smoking status & & & & & & $<0.001$ \\
\hline Current & $204(57.0 \%)$ & 194 (25.3\%) & 0 & 0 & 398 & \\
\hline Past & I54 (43.0\%) & $572(74.7 \%)$ & 0 & 0 & 726 & \\
\hline Passive & 0 & 0 & 75 & 301 & 376 & \\
\hline Smoking index (pack-years) & $33.6 \pm 20.6$ & $31.0 \pm 22.3$ & 0 & 0 & & $<0.001$ \\
\hline Positive respiratory symptoms* & 358 & 0 & 75 & 0 & 433 & $<0.001$ \\
\hline \multicolumn{7}{|l|}{ Lifestyle-related disease } \\
\hline Hypertension & $93(26.0 \%)$ & $564(73.6 \%)$ & $15(20.0 \%)$ & $232(77.1 \%)$ & 904 & $<0.001$ \\
\hline $\mathrm{AP} / \mathrm{MI}$ & $14(3.9 \%)$ & $64(8.4 \%)$ & I (I.3\%) & $6(2.0 \%)$ & 85 & $<0.001$ \\
\hline Diabetes mellitus & $19(5.3 \%)$ & $14 \mid(\mid 8.4 \%)$ & $5(6.7 \%)$ & $28(9.3 \%)$ & 193 & $<0.001$ \\
\hline Dyslipidemia & $30(8.4 \%)$ & $143(18.7 \%)$ & $9(12.0 \%)$ & 99 (32.9\%) & 281 & $<0.001$ \\
\hline Osteoporosis & I (0.3\%) & $22(2.9 \%)$ & I (I.3\%) & $36(12.0 \%)$ & 60 & $<0.001$ \\
\hline
\end{tabular}

Notes: *Positive respiratory symptoms include cough, cough producing sputum, and dyspnea on effort. Group A, positive smoking history, positive chronic respiratory symptoms; group B, no chronic respiratory symptoms, positive lifestyle-related disease; group C, passive smoking history, positive chronic respiratory symptoms; group D, passive smoking history, no chronic respiratory symptoms, positive lifestyle-related disease.

Abbreviations: COPD, chronic obstructive pulmonary disease; AP, angina pectoris; MI, myocardial infarction.

Table 2 COPD classification and pulmonary function testing results

\begin{tabular}{|c|c|c|c|c|c|c|}
\hline & $\begin{array}{l}\text { Group A } \\
(n=358)\end{array}$ & $\begin{array}{l}\text { Group B } \\
(n=766)\end{array}$ & $\begin{array}{l}\text { Group C } \\
(n=75)\end{array}$ & $\begin{array}{l}\text { Group D } \\
(n=30 I)\end{array}$ & Total & $P$-value \\
\hline COPD (FEV /FVC < 70\%), n (\%) & $47(13.1)$ & $96(12.5)$ & $5(6.7)$ & $23(7.6)$ & 171 & 0.048 \\
\hline Mild COPD & $8(17.0)$ & $28(29.2)$ & $3(60.0)$ & $8(34.8)$ & $47(27.0)$ & - \\
\hline Moderate COPD & $31(66.0)$ & $58(60.4)$ & $2(40.0)$ & $14(60.9)$ & $105(6 \mid .4)$ & 0.0372 \\
\hline Severe COPD & $7(14.9)$ & $10(10.4)$ & 0 & I (4.3) & $18(10.5)$ & \\
\hline Very severe COPD & I (2.I) & 0 & 0 & 0 & I (0.6) & \\
\hline $\mathrm{FEV}_{1} / \mathrm{FVC}, \mathrm{n}(\%)$ & & & & & & 0.185 \\
\hline$>70$ & $311(86.9)$ & $670(87.5)$ & $70(93.3)$ & $278(92.4)$ & I,329 (88.6) & \\
\hline $50-70$ & $45(12.6)$ & $92(12.0)$ & $5(6.7)$ & $23(7.6)$ & $165(11.0)$ & \\
\hline $30-50$ & $2(0.6)$ & $4(0.5)$ & 0 & 0 & $6(0.4)$ & \\
\hline$<30$ & 0 & 0 & 0 & 0 & 0 & \\
\hline Mean \pm standard deviation & $78.3 \pm 8.8$ & $78.0 \pm 8.5$ & $80.4 \pm 6.9$ & $79.5 \pm 7.3$ & $78.5 \pm 8.3$ & 0.003 \\
\hline Median & 78.9 & 78.4 & 80.5 & 80.2 & 79.2 & \\
\hline$\%$ predicted $\mathrm{FEV}_{1}, \mathrm{n}(\%)$ & & & & & & $<0.001$ \\
\hline$>80$ & $245(68.4)$ & $542(70.8)$ & $64(85.3)$ & $258(85.7)$ & I, 109 (73.9) & \\
\hline $50-80$ & $105(29.3)$ & $212(27.7)$ & II (I4.7) & $4 \mid(13.6)$ & $369(24.6)$ & \\
\hline $30-50$ & $7(2.0)$ & $12(1.6)$ & 0 & $2(0.7)$ & $21(1.4)$ & \\
\hline$<30$ & $\mathrm{I}(0.3)$ & 0 & 0 & 0 & $\mathrm{I}(0 . \mathrm{I})$ & \\
\hline Mean \pm standard deviation & $87.1 \pm 17.3$ & $88.0 \pm 16.3$ & $96.0 \pm 17.3$ & $97.0 \pm 17.5$ & $90.0 \pm 17.3$ & $<0.001$ \\
\hline Median & 87.3 & 88.5 & 96.6 & 97.7 & 90.6 & \\
\hline
\end{tabular}

Notes: COPD stage - mild, \% predicted $\mathrm{FEV},>80 \%$; moderate, $50 \%-80 \%$; severe, $30 \%-50 \%$; very severe, $<30 \%$.

Abbreviations: COPD, chronic obstructive pulmonary disease, $\mathrm{FEV}_{1}$, forced expiratory volume in I second; FVC, forced vital capacity. 
Table 3 Characteristics of COPD patients

\begin{tabular}{|c|c|c|c|c|c|c|}
\hline & $\begin{array}{l}\text { Group A } \\
(n=47)\end{array}$ & $\begin{array}{l}\text { Group B } \\
(n=96)\end{array}$ & $\begin{array}{l}\text { Group C } \\
(n=5)\end{array}$ & $\begin{array}{l}\text { Group D } \\
(n=23)\end{array}$ & Total & $P$-value \\
\hline Male/female & $44 / 3$ & $87 / 9$ & $1 / 4$ & $2 / 21$ & $134 / 37$ & $<0.001$ \\
\hline Male \% & $(93.6)$ & $(90.6)$ & $(20.0)$ & $(8.7)$ & $(78.4)$ & \\
\hline Age (years), n (\%) & & & & & & $<0.001$ \\
\hline $40-49$ & 0 & $\mathrm{I}(\mathrm{I} .0)$ & $2(40.0)$ & 0 & $3(1.8)$ & \\
\hline $50-59$ & $2(4.3)$ & $2(2.1)$ & I (20.0) & 0 & $5(2.9)$ & \\
\hline $60-69$ & $17(36.2)$ & $20(20.8)$ & I (20.0) & $10(43.5)$ & $58(33.9)$ & \\
\hline $70-79$ & $21(44.7)$ & $4 \mathrm{I}(42.7)$ & I (20.0) & $6(26.1)$ & $69(40.4)$ & \\
\hline $80+$ & $7(14.9)$ & $22(22.9)$ & 0 & $7(30.4)$ & $36(21.1)$ & \\
\hline Mean \pm standard deviation & $70.0 \pm 7.2$ & $72.8 \pm 8.2$ & $56.0 \pm 12.6$ & $72.7 \pm 8.7$ & $71.7 \pm 8.6$ & 0.015 \\
\hline Median & 70.0 & 73.5 & 57.0 & 71.0 & 71.0 & \\
\hline Smoking status, n (\%) & & & & & & $<0.001$ \\
\hline Current smoker & 27 (57.4\%) & 31 (32.3\%) & $0(0.0 \%)$ & $0(0.0 \%)$ & 58 (33.9\%) & \\
\hline Past smoker & $20(42.6)$ & 65 (67.7) & 0 & 0 & 85 (49.7) & \\
\hline Passive smoker & 0 & 0 & $5(100)$ & $23(100)$ & $28(16.4)$ & \\
\hline Smoking index (pack-years) & $48.8 \pm 22.1$ & $35.8 \pm 23.0$ & 0 & 0 & & $<0.001$ \\
\hline Positive respiratory symptoms* & 47 & 0 & 5 & 0 & 52 & $<0.001$ \\
\hline \multicolumn{7}{|l|}{ Lifestyle-related disease, n (\%) } \\
\hline Hypertension & $17(36.2)$ & $76(79.2)$ & I (20.0) & $15(65.2)$ & $109(63.7)$ & $<0.001$ \\
\hline AP/MI & 0 & $9(9.4)$ & 0 & 0 & $9(5.3)$ & 0.06 \\
\hline Diabetes mellitus & $3(6.4)$ & $15(15.6)$ & 0 & $2(8.7)$ & $20(11.7)$ & 0.31 \\
\hline Dyslipidemia & $3(6.4)$ & $10(10.4)$ & 0 & $9(39.1)$ & $22(12.9)$ & 0.001 \\
\hline Osteoporosis & 0 & 0 & 0 & $4(17.4)$ & $4(2.3)$ & $<0.001$ \\
\hline
\end{tabular}

Note: *Positive respiratory symptoms include cough, cough producing sputum, and dyspnea on effort.

Abbreviations: COPD, chronic obstructive pulmonary disease; AP, angina pectoris; MI, myocardial infarction.

Computed tomography data were collected from 152 participants who were diagnosed with COPD and underwent the examination for secondary evaluation. Figure 2 shows the relation between PFT data (percentage predicted $\mathrm{FEV}_{1}$ and $\mathrm{FEV}_{1} / \mathrm{FVC}$ ) and the emphysema score (Goddard classification). The emphysema score was not correlated with either the percentage predicted $\mathrm{FEV}_{1}$ or the $\mathrm{FEV}_{1} /$ FVC value.

Of the 171 patients with COPD, 124 (72.5\%) had moderate or worse disease requiring medical treatment. Subjects with a positive smoking history (groups A and B) had a significantly higher COPD detection rate (143 of 1,124, 12.7\%) compared with subjects who had a passive smoking history (groups C and D, 28 of 376, 7.4\%).

Univariate analysis of risk factors for COPD, according to patient sex and age, identified that a history of pulmonary disease was only a risk factor for COPD in patients younger than 60 years. In patients 60 years of age or older, a smoking index greater than 30 pack-years was a risk factor in males, and a history of pulmonary disease was a risk factor in females (Table 4). Multiple logistic regression analysis identified male sex, age 60 years or greater, and a positive smoking history as risk factors for COPD (Table 5). When risk analysis was conducted by sex in patients 60 years of age or older, the same risk factors as previously identified (a pack-year smoking index greater than 30 in males and a history of pulmonary disease in females) were confirmed to be independent risk factors for COPD (Table 6).

\section{Discussion}

The purpose of this project was to identify which individuals should be examined by PFT for the purpose of detecting COPD. Almost a quarter of study participants were considered to be COPD candidates and were recommended to undergo on-site PFT, and $11.4 \%$ of these were diagnosed with COPD. We therefore conclude that approximately $2.4 \%$ of Japanese individuals aged 40 years or older who undergo routine lung cancer screening may have COPD. Almost three-quarters of those with COPD were staged as moderate or worse and required medical treatment. Those with a positive personal smoking history were significantly more likely to have COPD than those with a passive smoking history. Although COPD patients frequently have comorbid lifestyle-related disease, these diseases did not prove to be risk factors for COPD in our study. The diagnosis rate of COPD rapidly increased in patients 60 years of age or older. From these results, we can suggest that individuals in this age-group with a positive smoking history should undergo PFT to detect COPD. By multivariate analysis, positive smoking history was not a risk factor for COPD. A smoking index more than 30 pack-years was only a 
A

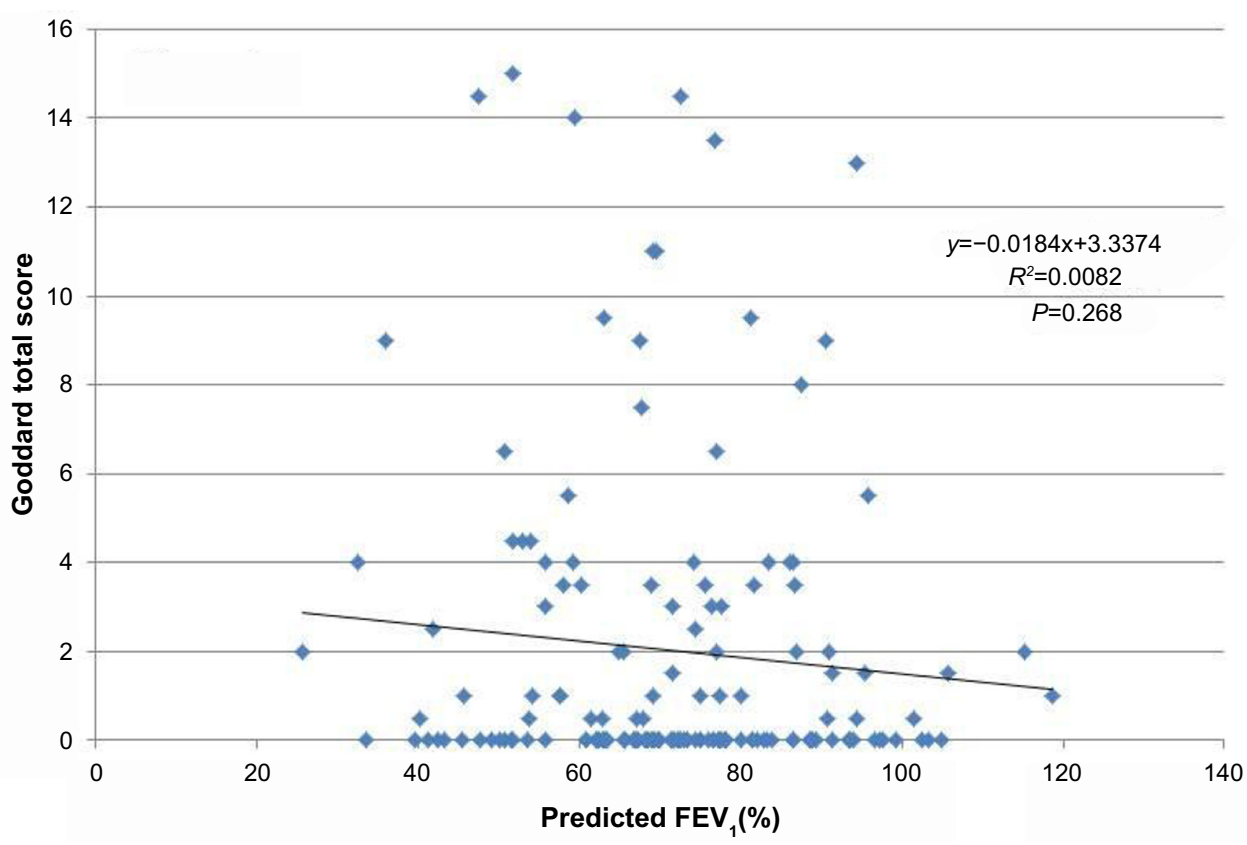

B

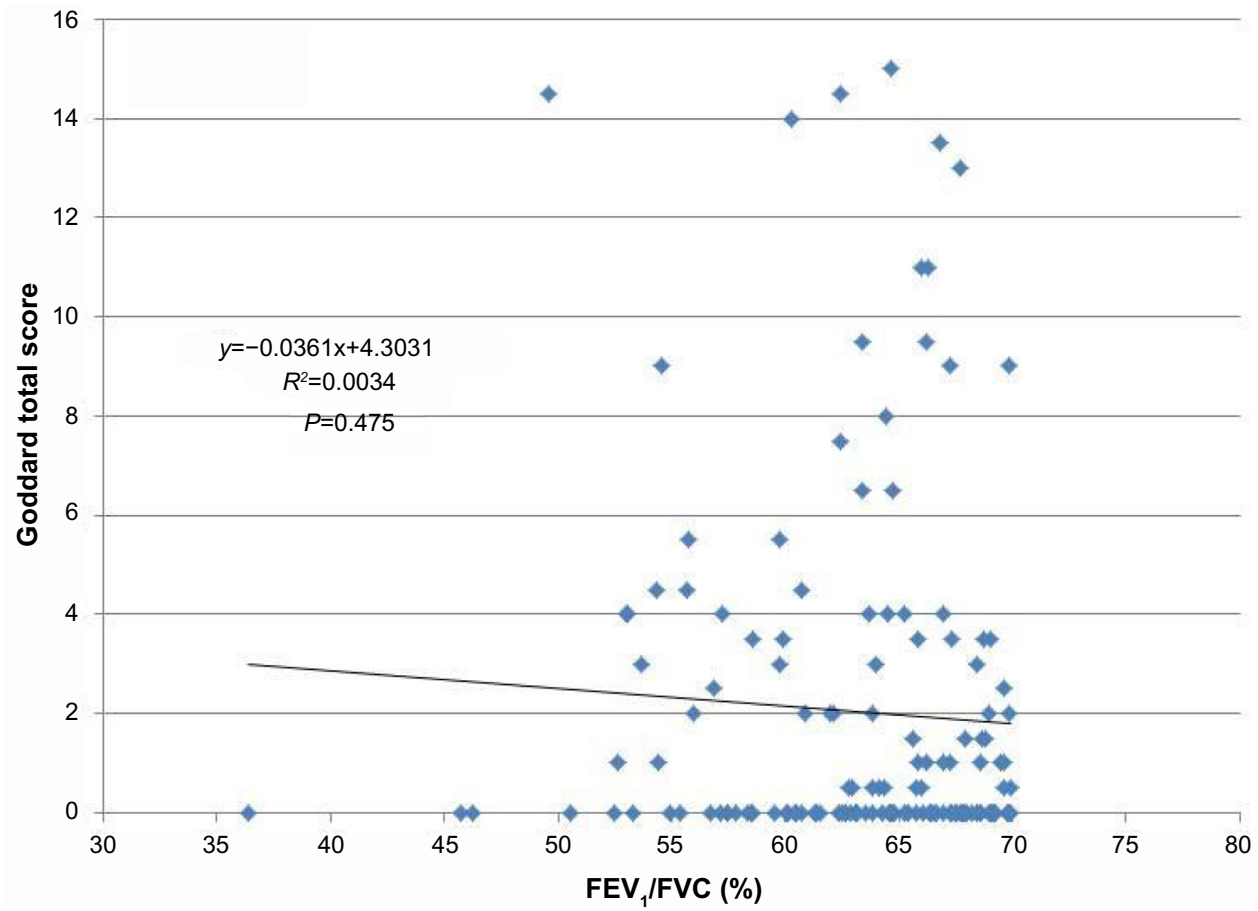

Figure 2 (A and B) Correlation between PFT and emphysema score (Goddard classification) in 152 participants who underwent both PFT and CT. The emphysema score was not correlated with either the percentage predicted $\mathrm{FEV}_{1}(P=0.268)$ or the $\mathrm{FEV}_{1} / \mathrm{FVC}(P=0.475)$ values. (A) Percentage predicted FEV; $(\mathbf{B}) \mathrm{FEV} / \mathrm{FVC}$.

Abbreviations: PFT, pulmonary function testing; CT, computed tomography; FEV , forced expiratory volume in I second; FVC, forced vital capacity.

risk factor for males. This may be because 1,067 participants (groups B and D) did not have any respiratory symptoms. Therefore, we cannot say that females with smoking history do not need PFT for COPD screening.

We previously reviewed the association between COPD and lung cancer, and proposed that early detection of COPD is important for lung cancer surveillance. ${ }^{15}$ The present study is the second to describe the utilization of regional mass screening for lung cancer to detect COPD. ${ }^{16}$ Of course, screening programs are clearly targeted at specific disease entities. For example, lung cancer screening is designed to detect early stage lung cancer, and the questionnaires and radiological examinations are focused on detecting that disease. However, patient age, smoking history, and the presence of chronic respiratory symptoms are important history items for both lung cancer and COPD. In fact, a positive smoking history 
Table 4 Univariate analysis of risk factors for COPD according to sex and age

\begin{tabular}{|c|c|c|c|c|c|c|}
\hline & \multicolumn{3}{|l|}{ Male } & \multicolumn{3}{|l|}{ Female } \\
\hline & Non-COPD (\%) & COPD (\%) & $P$-value & Non-COPD (\%) & COPD (\%) & $P$-value \\
\hline Younger than 60 years & $n=133$ & $\mathrm{n}=4$ & & $\mathrm{n}=165$ & $\mathrm{n}=4$ & \\
\hline Smoking index ( $>30$ pack-years) & 45.1 & 50.0 & 0.847 & 11.5 & 0 & $0.47 \mathrm{I}$ \\
\hline Positive respiratory symptoms* & 57.9 & 50.0 & 0.753 & 43.6 & 75.0 & 0.212 \\
\hline Smoking status & & & 0.382 & & & 0.343 \\
\hline Current smoker & 54.9 & 25.0 & & 29.1 & 0 & \\
\hline Past smoker & 40.6 & 75.0 & & 28.5 & 25.0 & \\
\hline Passive smoker & 4.5 & 0 & & 42.4 & 75.0 & \\
\hline Lifestyle-related disease & 54.9 & 50.0 & 0.847 & 61.8 & 50.0 & 0.631 \\
\hline Hypertension & 33.8 & 25.0 & 0.712 & 41.2 & 50.0 & 0.724 \\
\hline AP/MI & 4.5 & 0 & 0.664 & 0.6 & 0.0 & 0.876 \\
\hline Diabetes mellitus & 11.3 & 0 & 0.477 & 5.5 & 0 & 0.631 \\
\hline Dyslipidemia & 17.3 & 25.0 & 0.690 & 15.8 & 0 & 0.388 \\
\hline Osteoporosis & 0 & 0 & & 7.3 & 0 & 0.576 \\
\hline History of pulmonary disease & 12.0 & 50.0 & 0.027 & 13.9 & 50.0 & 0.045 \\
\hline Lung cancer & 0 & 0 & & 0 & 0 & \\
\hline Tuberculosis & 0 & 0 & & 0 & 25.0 & 0.000 \\
\hline Emphysema & 0 & 0 & & 0 & 0 & \\
\hline Pneumonia & 5.3 & 0.0 & 0.638 & 2.4 & 50.0 & 0.000 \\
\hline Asthma & 4.5 & 50.0 & 0.000 & 9.1 & 50.0 & 0.007 \\
\hline Pleurisy & 0 & 0 & & 0 & 0 & \\
\hline Chronic bronchitis & 3.0 & 0 & 0.725 & 2.4 & 0 & 0.753 \\
\hline 60 years of age or older & $n=659$ & $n=130$ & & $n=372$ & $\mathrm{n}=33$ & \\
\hline Smoking index ( $>30$ pack-years) & 56.2 & 70.8 & 0.002 & 13.2 & 6.1 & 0.238 \\
\hline Positive respiratory symptoms* & 24.9 & 33.1 & 0.052 & 18.3 & 12.1 & 0.375 \\
\hline Smoking status & & & 0.003 & & & 0.800 \\
\hline Current smoker & 24.7 & 39.2 & & 15.1 & 18.2 & \\
\hline Past smoker & 71.2 & 58.5 & & 19.1 & 15.2 & \\
\hline Passive smoker & 4.1 & 2.3 & & 65.9 & 66.7 & \\
\hline Lifestyle-related disease & 85.0 & 80.8 & 0.228 & 88.7 & 90.9 & 0.700 \\
\hline Hypertension & 66.6 & 67.7 & 0.812 & 65.3 & 54.5 & 0.215 \\
\hline AP/MI & 9.3 & 6.2 & 0.252 & 2.2 & 3.0 & 0.742 \\
\hline Diabetes mellitus & 17.8 & 13.8 & 0.280 & 8.6 & 6.1 & 0.614 \\
\hline Dyslipidemia & 14.0 & 6.9 & 0.028 & 31.7 & 36.4 & 0.584 \\
\hline Osteoporosis & 0.9 & 0.0 & 0.275 & 10.2 & 12.1 & 0.731 \\
\hline History of pulmonary disease & 12.8 & 14.6 & 0.572 & 12.9 & 30.3 & 0.006 \\
\hline Lung cancer & 0.2 & 0 & 0.657 & 0 & 0 & \\
\hline Tuberculosis & 3.3 & 3.8 & 0.771 & 1.3 & 0 & 0.503 \\
\hline Emphysema & 0.6 & 2.3 & 0.059 & 0 & 0 & \\
\hline Pneumonia & 4.2 & 0.8 & 0.054 & 3.2 & 3.0 & 0.951 \\
\hline Asthma & I.I & 4.6 & 0.004 & 3.8 & 12.1 & 0.026 \\
\hline Pleurisy & 1.7 & 0.0 & 0.138 & 0.8 & 3.0 & 0.216 \\
\hline Chronic bronchitis & 1.5 & 0.8 & 0.506 & 2.7 & 9.1 & 0.046 \\
\hline
\end{tabular}

Note: *Positive respiratory symptoms include cough, cough producing sputum, and dyspnea on effort.

Abbreviations: COPD, chronic obstructive pulmonary disease; AP, angina pectoris; MI, myocardial infarction.

and chronic respiratory symptoms are reportedly crucial factors that should trigger clinicians to suspect COPD. ${ }^{17,18}$ Therefore, we expected that COPD could be detected using the lung cancer mass-screening program, with a small additional expense for PFT at the primary evaluation.

The prevalence of COPD in the general population is thought to be about $1 \%$, and the prevalence increases to
$8 \%-10 \%$ of the population over 40 years of age.${ }^{19}$ In this study, approximately $2.4 \%$ of all participants aged 40 years or older who underwent routine lung cancer screening may have COPD. This seems to be a lower detection rate than other cohorts. ${ }^{4}, 19$ However, $11.4 \%$ of the COPD candidates in this study were diagnosed with COPD. Furthermore, by focusing on smokers (groups A and B), 12.7\% of participants (143 of 1,124) were 
Table 5 Multivariate analysis of risk factors for COPD

\begin{tabular}{|c|c|c|c|c|c|}
\hline Variables & $\beta$ & Wald & $\begin{array}{l}\text { Hazard } \\
\text { ratio }\end{array}$ & $95 \% \mathrm{Cl}$ & P-value \\
\hline Sex (male) & 0.656 & 6.014 & 1.928 & I. $14 \mid-3.257$ & 0.014 \\
\hline Age ( $>60$ years) & 1.652 & 19.248 & 5.215 & $2.494-10.907$ & 0.000 \\
\hline Smoking index ( $>30$ pack-years) & 0.452 & 5.396 & I.57| & $1.073-2.300$ & 0.020 \\
\hline History of pulmonary disease* & 0.489 & 5.016 & 1.630 & $1.063-2.500$ & 0.025 \\
\hline Group & 1.306 & & & & \\
\hline Group C & & & I & Reference & \\
\hline Group A & -0.109 & 0.040 & 0.897 & $0.309-2.603$ & 0.841 \\
\hline Group B & -0.305 & 0.331 & 0.737 & $0.26 I-2.084$ & 0.565 \\
\hline Group D & -0.095 & 0.033 & 0.910 & $0.327-2.530$ & 0.856 \\
\hline
\end{tabular}

Note: *History of pulmonary disease includes lung cancer, tuberculosis, emphysema, pneumonia, asthma, pleurisy, and chronic bronchitis.

Abbreviations: COPD, chronic obstructive pulmonary disease; $\mathrm{Cl}$, confidence interval.

diagnosed with COPD. This means that our screening system can obtain the same detection rate as other trials.

In our study, the PFT participation rate was very high, allowing the diagnosis of COPD to be made at the time of initial screening. Lyngsø et al reported the use of a simple postal questionnaire containing questions about risk factors to screen for COPD. ${ }^{18}$ Although the rates of COPD risk and actual, spirometry-confirmed COPD were 58.5\% (3,376 of 5,767) and $10.3 \%$ (596 of 5,767), respectively, the rate of participation in PFT was only $40.0 \%$ (1,352 of 3,376), perhaps because of the time-consuming nature of the spirometry appointment. In our study, $89 \%$ of the subjects at risk for COPD were able to undergo PFT at the time of initial screening, as testing was immediately available on site. Since a high participation rate is crucial for the effect of screening to be felt in a population, and is a requirement for the implementation of organized screening, our on-site program seems ideal.

In this study, we considered individuals with a passive smoking history and lifestyle-related disease to be at risk for COPD. Jordan et al reported that increasing passive smoke exposure is independently associated with an increased risk for COPD. ${ }^{20}$ Certain comorbidities, including lifestyle-related diseases, are also more likely to be present in COPD patients. ${ }^{9}$ Therefore, we hypothesized that individuals with these factors present would have a relatively high prevalence of COPD. In actuality, we found that increasing age (60 years or older), a smoking index of 30 pack-years or more, and a history of pulmonary disease, but not lifestyle-related disease or passive smoking history, were significant risk factors for COPD. Therefore, nonactive smokers or individuals with lifestyle-related disease should not be a target for COPD screening. Of course, since COPD may be hidden in patients with lifestyle-related disease, general practitioners should pay attention to subtle symptoms and have a high index of suspicion for COPD.

In females, a history of pulmonary disease was a risk factor for COPD. A history of pulmonary disease includes lung cancer, tuberculosis, emphysema, pneumonia, asthma, pleurisy, and chronic bronchitis. Many pulmonary diseases interact with each other, and airway obstruction can be induced. Therefore, this result may suggest that patients who

Table 6 Multivariate analysis of risk factors for COPD in patients aged $>60$ years, according to sex

\begin{tabular}{|c|c|c|c|c|c|}
\hline Variables & $\beta$ & Wald & $\begin{array}{l}\text { Hazard } \\
\text { ratio }\end{array}$ & $95 \% \mathrm{Cl}$ & $P$-value \\
\hline \multicolumn{6}{|l|}{ Male $(n=786)$} \\
\hline Smoking index ( $>30$ pack-years) & 0.594 & 7.605 & 1.811 & $|| 87-2.76 \mid$. & 0.006 \\
\hline Positive smoking history & 0.165 & 0.067 & 1.179 & $0.339-4.099$ & 0.795 \\
\hline Lifestyle-related disease* & -0.333 & 2.507 & 0.716 & $0.474-1.083$ & 0.113 \\
\hline History of pulmonary disease ${ }^{\#}$ & 0.087 & 0.097 & 1.091 & $0.631-1.884$ & 0.756 \\
\hline \multicolumn{6}{|l|}{ Female $(n=405)$} \\
\hline Smoking index ( $>30$ pack-years) & -1.058 & 1.697 & 0.347 & $0.07 I-1.705$ & 0.193 \\
\hline Positive smoking history & 0.266 & 0.392 & 1.304 & $0.568-2.996$ & 0.531 \\
\hline Lifestyle-related disease* & 0.705 & 1.510 & 2.023 & $0.658-6.224$ & 0.219 \\
\hline History of pulmonary disease & 1.216 & 8.277 & 3.374 & I.473-7.725 & 0.004 \\
\hline
\end{tabular}

Notes: *Lifestyle-related disease includes hypertension, angina pectoris/myocardial infarction, diabetes mellitus, dyslipidemia, and osteoporosis; " history of pulmonary disease includes lung cancer, tuberculosis, emphysema, pneumonia, asthma, pleurisy, and chronic bronchitis.

Abbreviations: COPD, chronic obstructive pulmonary disease; $\mathrm{Cl}$, confidence interval. 
had any pulmonary disease should confirm the possibility of airway obstruction.

There are several limitations to our study. We adopted the criterion of $\mathrm{FEV}_{1} / \mathrm{FVC}$ less than $70 \%$, without the use of bronchodilators, to define COPD. A simple fixed $\mathrm{FEV}_{1} /$ FVC ratio (the GOLD definition) used to define lung-function impairment has been shown to overestimate COPD with increasing age, particularly among men, compared with such statistical approaches as the lower limit of normal. ${ }^{21}$ Therefore, our COPD definition might have been inaccurate in patients of advanced age. However, the GOLD criterion is a clear, easy-to-understand recommendation. Spirometry without the use of bronchodilators may also have resulted in overestimation of airflow limitation. However, the more complicated and difficult technique involved with bronchodilator testing is not appropriate for a screening examination. Therefore, subjects who are diagnosed with COPD on screening should be examined more precisely by a pulmonologist at the secondary evaluation for a definitive diagnosis and treatment plan.

In our study, we did not calculate the actual cost at the screening. However, we were able to limit COPD candidates by questionnaires without any expense. Salameh et al reported that they created a diagnosis score for COPD, and clarified the usefulness of this score without spirometry for detection of COPD. ${ }^{22}$ We also performed PFT only for the participants who were suspected to be at high risk for COPD. Furthermore, data from Haroon et al are instructive, as they compared the yield and cost-effectiveness of two COPD case-finding approaches for ever-smokers aged 35-79 years with no history of COPD or asthma in primary care. ${ }^{23}$ They reported that respiratory questionnaires were posted to patients in the "targeted" arm and provided to patients in the "opportunistic" arm at routine general practitioner appointments. Patients allocated to the targeted arm were sent an invitation letter, respiratory questionnaire, consent form, and a prepaid return envelope in the post by the research team. In the opportunistic arm, electronic prompts were added to medical records to provide the same questionnaire pack when patients next presented to their general practitioner or practice nurse. They concluded that opportunistic case finding may be more effective and cost-effective than targeting patients with a postal questionnaire alone. These results suggest that PFT should be done only for high-risk individuals in community-based mass screening.

In conclusion, COPD can be effectively detected using an established community-based lung cancer-screening program. Individuals 60 years of age or older with a positive smoking history should undergo PFT to detect COPD. After COPD is identified on screening, further precise diagnostic assessment is required for correct staging and treatment decisions. We should note that because both COPD and lung cancer have high mortality rates and incur severe economic burdens, encouragement of smoking cessation and early detection and intervention for both diseases should be initiated through these screenings.

\section{Acknowledgments}

We greatly appreciate the efforts of the participating community residents and physicians involved in both the screening and secondary evaluations. This work was supported by a Grant-in-Aid for Scientific Research (23592075) from the Ministry of Education, Culture, Sports, Science and Technology of Japan.

\section{Disclosure}

The authors report no conflicts of interest in this work.

\section{References}

1. Bednarek M, Maciejewski J, Wozniak M, Kuca P, Zielinski J. Prevalence, severity and underdiagnosis of COPD in the primary care setting. Thorax. 2008;63:402-407.

2. Soriano JB, Zielinski J, Price D. Screening for and early detection of chronic obstructive pulmonary disease. Lancet. 2009;374:721-732.

3. Rabe KF, Hurd S, Anzueto A, et al. Global strategy for the diagnosis, management, and prevention of chronic obstructive pulmonary disease: GOLD executive summary. Am J Respir Crit Care Med. 2007;176: 532-555.

4. Fukuchi Y, Nishimura M, Ichinose M, et al. COPD in Japan: the Nippon COPD Epidemiology study. Respirology. 2004;9:458-465.

5. Joo MJ, Lee TA, Weiss KB. Geographic variation of spirometry use in newly diagnosed COPD. Chest. 2008;134:38-45.

6. Bolton CE, Ionescu AA, Edwards PH, Faulkner TA, Edwards SM, Shale DJ. Attaining a correct diagnosis of COPD in general practice. Respir Med. 2005;99:493-500.

7. Turner MC, Chen Y, Krewski D, Calle EE, Thun MJ. Chronic obstructive pulmonary disease is associated with lung cancer mortality in a prospective study of never smokers. Am J Respir Crit Care Med. 2007;176:285-290.

8. Mapel DW, Hurley JS, Frost FJ, Petersen HV, Picchi MA, Coultas DB. Health care utilization in chronic obstructive pulmonary disease. A case-control study in a health maintenance organization. Arch Intern Med. 2000;160:2653-2658.

9. Chatila WM, Thomashow BM, Minai OA, Criner GJ, Make BJ. Comorbidities in chronic obstructive pulmonary disease. Proc Am Thorac Soc. 2008;5:549-555.

10. Nishii K, Ueoka H, Kiura K, et al. A case-control study of lung cancer screening in Okayama Prefecture, Japan. Lung Cancer. 2001;34: 325-332.

11. Tsukada H, Kurita Y, Yokoyama A, et al. An evaluation of screening for lung cancer in Niigata Prefecture, Japan: a population-based casecontrol study. Br J Cancer. 2001;85:1326-1331.

12. Global initiative for chronic Obstructive Lung Disease (GOLD). Global Strategy for the Diagnosis, Management, and Prevention of Chronic Obstructive Pulmonary Disease. Bethesda (MD): GOLD; 2013. Available from: http://www.goldcopd.org/uploads/users/files/ GOLD_Report_2013_Feb20.pdf. Accessed May 5, 2013. 
13. Goddard PR, Nicholson EM, Laszlo G, Watt I. Computed tomography in pulmonary emphysema. Clin Radiol. 1982;33:379-387.

14. Makita H, Nasuhara Y, Nagai K, et al. Characterization of phenotypes based on severity of emphysema in chronic obstructive pulmonary disease. Thorax. 2007;62:932-937.

15. Sekine Y, Katsura H, Koh E, Hiroshima K, Fujisawa T. Early detection of COPD is important for lung cancer surveillance. Eur Respir J. 2012;39:1230-1240.

16. Sekine Y, Fujisawa T, Suzuki K, et al. Detection of chronic obstructive pulmonary disease in community-based annual lung cancer screening: Chiba Chronic Obstructive Pulmonary Disease Lung Cancer Screening Study Group. Respirology. 2014;19:98-104.

17. Powell HA, Iyen-Omofoman B, Baldwin DR, Hubbard RB, Tata LJ. Chronic obstructive pulmonary disease and risk of lung cancer: the importance of smoking and timing of diagnosis. J Thorac Oncol. 2013;8:6-11.

18. Lyngsø AM, Gottlieb V, Backer V, et al. Early detection of COPD in primary care: the Copenhagen COPD screening project. COPD. 2013;10:208-215.
19. Halbert RJ, Natoli JL, Gano A, Badamgarav E, Buist AS, Mannino DM. Global burden of COPD: systematic review and meta-analysis. Eur Respir J. 2006;28:523-532.

20. Jordan RE, Cheng KK, Miller MR, Adab P. Passive smoking and chronic obstructive pulmonary disease: cross-sectional analysis of data from the Health Survey for England. BMJ Open. 2011;1:e00153.

21. Swanney MP, Ruppel G, Enright PL, et al. Using the lower limit of normal for the FEV1/FVC ratio reduces the misclassification of airway obstruction. Thorax. 2008;63:1046-1051.

22. Salameh P, Khayat G, Waked M. Could symptoms and risk factors diagnose COPD? Development of a diagnosis score for COPD. Clin Epidemiol. 2012;4:247-255.

23. Haroon S, Adab P, Griffin C, Jordan R. Case finding for chronic obstructive pulmonary disease in primary care: a pilot randomised controlled trial. Br J Gen Pract. 2013;63:e55-e62.

\section{Publish your work in this journal}

The International Journal of COPD is an international, peer-reviewed journal of therapeutics and pharmacology focusing on concise rapid reporting of clinical studies and reviews in COPD. Special focus is given to the pathophysiological processes underlying the disease, intervention programs, patient focused education, and self management protocols.

\section{Dovepress}

This journal is indexed on PubMed Central, MedLine and CAS. The manuscript management system is completely online and includes a very quick and fair peer-review system, which is all easy to use. Visit http://www.dovepress.com/testimonials.php to read real quotes from published authors. 